\title{
The evolutionary design of condensers
}

A. Bejan, , J. Lee, , S. Lorente, and, and Y. Kim

Citation: Journal of Applied Physics 117, 125101 (2015); doi: 10.1063/1.4915505

View online: http://dx.doi.org/10.1063/1.4915505

View Table of Contents: http://aip.scitation.org/toc/jap/117/12

Published by the American Institute of Physics

\section{AIP | Journal of A1P Applied Physics}

Save your money for your research.

It's now FREE to publish with us -

no page, color or publication charges apply.
Publish your research in the

Joumal of Applied Physics

to claim your place in applied

physics history. 


\title{
The evolutionary design of condensers
}

\author{
A. Bejan, ${ }^{1, a)}$ J. Lee, ${ }^{2}$ S. Lorente, ${ }^{3}$ and Y. Kim ${ }^{2}$ \\ ${ }^{1}$ Department of Mechanical Engineering and Materials Science, Duke University, Durham, \\ North Carolina 27708-0300, USA \\ ${ }^{2}$ Doosan Heavy Industries \& Construction Co., Ltd., 22 Doosan Volvo-ro, Seongsan-gu, Changwon, \\ Gyeongnam, South Korea \\ ${ }^{3}$ Université de Toulouse, INSA, 135 Avenue de Rangueil, 31077 Toulouse, France
}

(Received 19 December 2014; accepted 2 March 2015; published online 24 March 2015)

\begin{abstract}
Condensers are flow architectures needed to provide high rates of condensation (or cooling) per unit volume, in enclosures with fixed volume. Their design has not changed from configurations consisting of the banks of horizontal tubes. In this paper, we outline a free path to evolving the design by exploring new features of flow configuration: flattened tubes, multiple tube sizes, arrays of flattened tubes, vertical tubes with turbulent film flow, forced convection condensation instead of gravity driven condensation, and the optimal length of a horizontal tube, i.e., the number of tubes in a column aligned with vapor cross flow. We show that the condensation density can be increased sizably by varying freely and without bias the morphology of the flow system: the shapes and arrangement of the cooled surfaces on which condensation occurs. The evolution of technology is described in terms of the special time direction of the useful (purposeful) changes in the configuration (shapes, arrangements) of surfaces on which flow/condensation occurs. This explains what "evolution" means. It is an important step for physics, not just technology. (C) 2015 AIP Publishing LLC. [http://dx.doi.org/10.1063/1.4915505]
\end{abstract}

\section{METHOD}

In this paper, we explore the evolutionary improvements that can be made in the architecture and performance of large scale condensers for steam power plants. ${ }^{1-6}$ The focus is on fundamentals. The approach is based on constructal design, ${ }^{7-9}$ which is the view that improvements in global performance are achievable through changes in the architecture of the flow system, to facilitate flow. For this purpose, the flow architecture must be free to morph, such that better and better flow architectures can be pursued relentlessly.

What designers view as "optimal" is the light at the end of the tunnel, the direction in which the architectural changes are pointing, over time. ${ }^{10}$ The direction is natural, and is exhibited by all evolutionary designs, the flow architectures of nature, and the evolution of technology.

The evolution of the snowflake illustrates the natural character of design evolution. ${ }^{7,11}$ The snowflake is an architecture that morphs as the surrounding subcooled water vapor becomes solid at a nucleation site. This evolutionary design phenomenon is known as dendritic solidification, or rapid solidification. In the simplest case (Fig. 1), the system contains a single pure substance (water). The vapor flows from all directions and sinks into the solid surfaces that grow around the initial nucleation site.

The changes in the geometry of the growing solid are continuous, not discontinuous. These changes occur with purpose, which is to facilitate the flow of heat from the solid surface to the surroundings. Initially, the solid is a tiny spherical bead. Later, the solid grows as needles that acquire new

\footnotetext{
a) Author to whom correspondence should be addressed. Electronic mail: abejan@duke.edu
}

needles (branches) as they grow. The purpose of these changes in geometry during growth is to increase- to accelerate- the rate of solidification. The growing sphere offers the greater solidification rate when the solid is small. The solid with growing tree with branches offers the greater solidification rate when the solid is large.

Steam condensers are emerging from evolutionary design that is analogous to and less evident than the evolution of the snowflake design. To shed light on condenser design evolution is the purpose of this article. Consider the condensation phenomenon sketched in Fig. 2. The pure substance (water) flows from all directions and sinks into the free surfaces of the liquid (the condensate) formed on solid surfaces that are maintained cold. The simplest and least expensive design is a single horizontal pipe with cooling water flowing through it. Unlike in the snowflake, the liquid does not grow continuously on the cold surface of the pipe. The liquid is removed steadily by the force of gravity, or by suction. Figure 2 reminds us that the designs of condensers have been evolving toward better architectures of cooled surfaces, such as multiple pipes arranged uniformly or nonuniformly. The evolutionary path outlined in this paper is the result of continuing this free evolutionary process, to the right of Fig. 2, over time. The evolutionary steps selected for this presentation are intentionally simple.

\section{OBJECTIVE}

In the design of the condenser, the objective is to produce the highest flow rate of condensate in a finite volume. It is to construct a flow architecture with high density of condensation or cooling. The way to achieve this is by discovering the flow architecture in three dimensions. Every design 

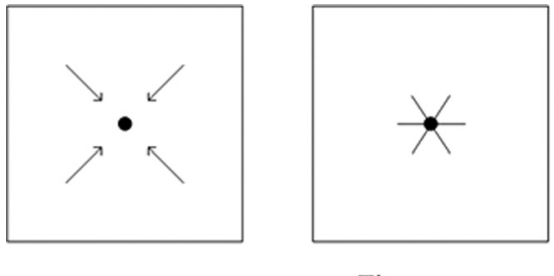

Time

FIG. 1. The evolutionary design of dendritic solidification.
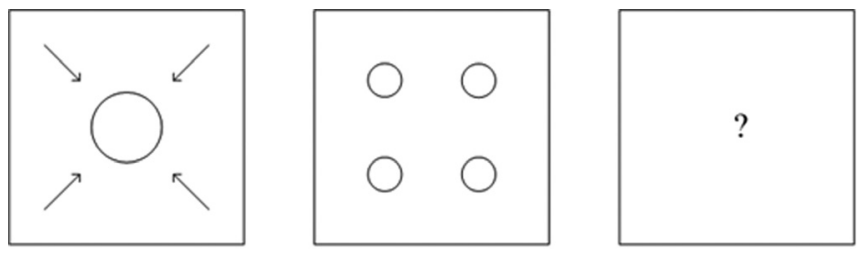

Time $\longrightarrow$

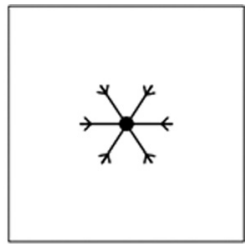

$$
\Gamma_{\mathrm{z}}=\frac{\mathrm{k}}{\mathrm{h}_{\mathrm{fg}}}\left(\mathrm{T}_{\mathrm{sat}}-\mathrm{T}_{\mathrm{w}}\right) \overline{\mathrm{Nu}_{\mathrm{z}}},
$$$$
\overline{\mathrm{Nu}_{\mathrm{z}}}=\frac{\overline{\mathrm{q}^{\prime \prime} \mathrm{z}}}{\mathrm{k}\left(\mathrm{T}_{\mathrm{sat}}-\mathrm{T}_{\mathrm{w}}\right)}=\frac{\mathrm{h}_{\mathrm{z}} \mathrm{z}}{\mathrm{k}} .
$$

Furthermore, if we eliminate $\overline{\mathrm{Nu}_{\mathrm{z}}}$ between Eqs. (5) and (6) we obtain the proportionality between mass flow rate and heat transfer coefficient,

$$
\mathrm{h}_{\mathrm{z}}=\frac{\Gamma_{\mathrm{z}} \mathrm{h}_{\mathrm{fg}}}{\mathrm{z}\left(\mathrm{T}_{\mathrm{sat}}-\mathrm{T}_{\mathrm{w}}\right)} .
$$

\section{HORIZONTAL CYLINDERS, GRAVITY DRIVEN FILM}

The benchmark and starting point is the classical result for laminar film condensation on a horizontal cylinder with laminar film of condensate. For a horizontal tube with external diameter $\mathrm{D}, \overline{\mathrm{Nu}}$ is given by ${ }^{12}$

$$
\overline{\mathrm{Nu}_{\mathrm{D}}}=0.729\left[\frac{\mathrm{D}^{3} \mathrm{~h}_{\mathrm{fg}}^{\prime} \mathrm{g} \rho}{\mathrm{k} \nu\left(\mathrm{T}_{\mathrm{sat}}-\mathrm{T}_{\mathrm{w}}\right)}\right]^{1 / 4} .
$$

feature varies, except the fact that the cold surfaces are bathed on the cold side by cooling water, and on the warm side by saturated steam at $\mathrm{T}_{\text {sat }}$.

The numerical examples are based on dimensions and operating conditions that characterize current designs: $\mathrm{T}_{\text {sat }}=38.4^{\circ} \mathrm{C}$ and a surface temperature of $\mathrm{T}_{\mathrm{w}}=30^{\circ} \mathrm{C}$. The properties of saturated liquid water at $38.4^{\circ} \mathrm{C}$ are approximately: ${ }^{12} \rho \cong 1000 \mathrm{~kg} / \mathrm{m}^{3}, \quad \mu \cong 0.0066 \mathrm{~g} / \mathrm{cm} \mathrm{s}, \quad \nu \cong 0.0066$ $\mathrm{cm}^{2} / \mathrm{s}, \alpha \cong 0.0015 \mathrm{~cm}^{2} / \mathrm{s}, \mathrm{c}_{\mathrm{P}} \cong 4.18 \mathrm{~kJ} / \mathrm{kgK}, \mathrm{k} \cong 0.63 \mathrm{~W} / \mathrm{m} \mathrm{K}$, $\mathrm{h}_{\mathrm{fg}} \cong 2400 \mathrm{~kJ} / \mathrm{kg}, \quad \operatorname{Pr}=4.4$. The tube outer diameter is $\mathrm{D}=2 \mathrm{~cm}$.

In general, according to the first law of thermodynamics, the mass flow rate of condensate generated by a cold surface is $^{12}$

$$
\Gamma=\frac{\mathrm{q}^{\prime}}{\mathrm{h}_{\mathrm{fg}}^{\prime}},
$$

where $\mathrm{q}^{\prime}[\mathrm{W} / \mathrm{m}]$ and $\Gamma[\mathrm{kg} /(\mathrm{sm})]$ are the cooling rate and mass flow rate expressed per unit length in the horizontal direction. The denominator $\mathrm{h}_{\mathrm{fg}}^{\prime}$ is the augmented latent heat of condensation, $\mathrm{h}_{\mathrm{fg}}^{\prime}=\mathrm{h}_{\mathrm{fg}}+0.68 \mathrm{c}_{\mathrm{P}}\left(\mathrm{T}_{\text {sat }}-\mathrm{T}_{\mathrm{w}}\right)$, which for the property values listed above is only $1 \%$ greater than $\mathrm{h}_{\mathrm{fg}}$. In the following analysis, we use $\mathrm{h}_{\mathrm{fg}}^{\prime} \cong \mathrm{h}_{\mathrm{fg}}$. Equation (1) is also expressed as

$$
\Gamma=\frac{\mathrm{k}}{\mathrm{h}_{\mathrm{fg}}}\left(\mathrm{T}_{\mathrm{sat}}-\mathrm{T}_{\mathrm{w}}\right) \overline{\mathrm{Nu}},
$$

where $\overline{\mathrm{Nu}}$ is the overall Nusselt number,

$$
\overline{\mathrm{Nu}}=\frac{\mathrm{q}^{\prime}}{\mathrm{k}\left(\mathrm{T}_{\mathrm{sat}}-\mathrm{T}_{\mathrm{w}}\right)} .
$$

If the film of condensate travels the length $z$, then Eqs. (1)-(3) are rewritten as

$$
\Gamma_{\mathrm{z}}=\frac{\mathrm{q}_{\mathrm{z}}^{\prime}}{\mathrm{h}_{\mathrm{fg}}^{\prime}}=\frac{\overline{\mathrm{q}^{\prime \prime}} \mathrm{z}}{\mathrm{h}_{\mathrm{fg}}^{\prime}},
$$

The effect of organization (design) on condensation density is already evident in the performance of cylinders arranged in a vertical column, Fig. 3. The cooling rate for the entire column is

$$
\mathrm{q}_{\mathrm{nD}}^{\prime}=\mathrm{n} \pi \mathrm{D}\left(\mathrm{T}_{\mathrm{sat}}-\mathrm{T}_{\mathrm{w}}\right) \overline{\mathrm{h}_{\mathrm{Dn}}},
$$

where the column-averaged heat transfer coefficient and the total condensation rate are

$$
\overline{\mathrm{h}_{\mathrm{Dn}}}=\frac{\overline{\mathrm{h}_{\mathrm{D}}}}{\mathrm{n}^{1 / 4}}, \quad \overline{\mathrm{h}_{\mathrm{D}}}=\frac{\mathrm{k}}{\mathrm{D}} \overline{\mathrm{Nu}_{\mathrm{D}}}, \quad \Gamma_{\mathrm{nD}}=\frac{\mathrm{q}_{\mathrm{DD}}^{\prime}}{\mathrm{h}_{\mathrm{fg}}} .
$$

The first of Eq. (10) is from Eq. (10.32) in Ref. 12. The column-averaged condensation density decreases as the
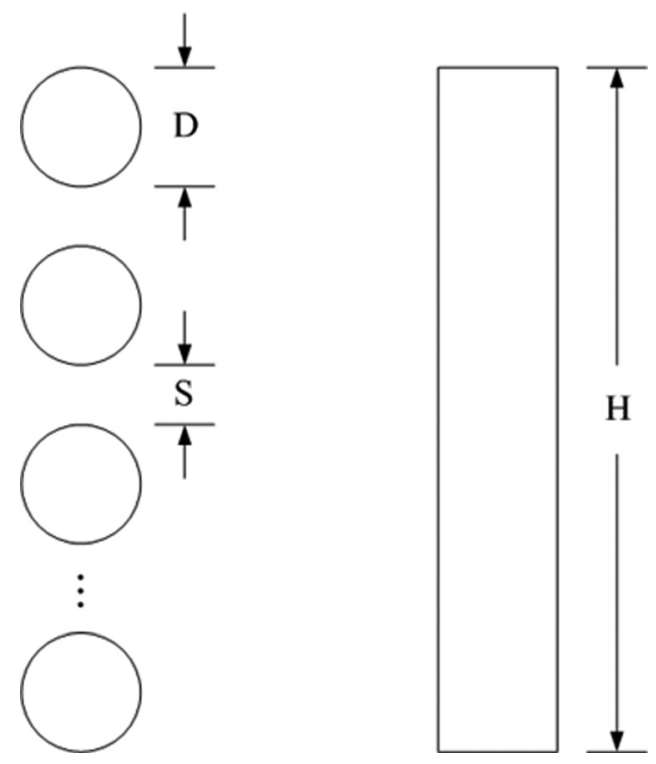

FIG. 3. Vertical column of horizontal cylinders, and a vertical slab of the same height. 
number of cylinders (n) increases. Note that in the limit of increasing $\mathrm{n}$ and decreasing $\mathrm{D}$, the column resembles a vertical slab of height $\mathrm{H}$ and thickness $\mathrm{D}$, for which

$$
\overline{\mathrm{Nu}_{\mathrm{H}}}=0.943\left[\frac{\mathrm{H}^{3} \mathrm{~h}_{\mathrm{fg}} \mathrm{g} \rho}{\mathrm{k} \nu\left(\mathrm{T}_{\mathrm{sat}}-\mathrm{T}_{\mathrm{w}}\right)}\right]^{1 / 4} .
$$

The cooling rate into one side of the $\mathrm{H}$-tall slab is $\mathrm{q}_{\mathrm{H}}^{\prime}=\mathrm{k}\left(\mathrm{T}_{\mathrm{sat}}-\mathrm{T}_{\mathrm{w}}\right) \overline{\mathrm{Nu}_{\mathrm{H}}}$. The slab has two sides, therefore, the total condensation rate is $\Gamma_{\mathrm{H}}=2 \mathrm{q}_{\mathrm{H}}^{\prime} / \mathrm{h}_{\mathrm{fg}}$. If we neglect the spacings between tubes and approximate $\mathrm{H} \sim \mathrm{nD}$, then we compare $\Gamma_{\mathrm{nD}}$ with $\Gamma_{\mathrm{H}}$ and we find that the two estimates are almost the same, $\Gamma_{\mathrm{H}} \cong 0.82 \Gamma_{\mathrm{nD}}$.

If the volume has the square vertical cross section $\mathrm{A}$ with $n$ vertical columns in which each cylinder occupies an elemental square with the side $\sigma \mathrm{D}$, where $\sigma \geq 1$, Fig. 4 , then the rate of condensate produced over the cross section $\mathrm{A}$ is

$$
\Gamma_{\mathrm{A}}=\mathrm{n} \Gamma_{\mathrm{nD}}=\mathrm{n} \cdot \mathrm{n}^{3 / 4} \pi \Gamma_{\mathrm{D}}=\mathrm{n}^{7 / 4} \pi \Gamma_{\mathrm{D}} .
$$

The volumetric rate of condensation is

$$
\frac{\Gamma_{\mathrm{A}}}{\mathrm{A}}=\mathrm{n}^{-1 / 4} \frac{\pi}{\sigma^{2}} \frac{\Gamma_{\mathrm{D}}}{\mathrm{D}^{2}} .
$$

Because $\Gamma_{\mathrm{D}}$ is proportional to $\mathrm{D}^{3 / 4}$, we conclude that the volumetric rate of condensation is proportional to $n^{-1 / 4} D^{-5 / 4}$, which means that smaller tube diameters are better, and fewer tubes (n) are marginally better.

\section{FLAT TUBE CROSS SECTIONS}

According to constructal design, ${ }^{7-9}$ the flow configuration is free to change in the pursuit of greater access for what flows (cf. Sec. I). Consider changing the shape of the tube cross section from round (diameter $\mathrm{D}$ ) to flat and vertical (height $\mathrm{H}=\pi \mathrm{D} / 2$ ). The amount of tube wall material is the same in both designs (Fig. 5). Equation (8) shows that the total cooling rate (proportional to the condensation rate) on the round cylinder is

$$
\mathrm{q}_{\mathrm{D}}^{\prime}=\pi \mathrm{k}\left(\mathrm{T}_{\mathrm{sat}}-\mathrm{T}_{\mathrm{w}}\right) 0.729 \mathrm{aD}^{3 / 4},
$$

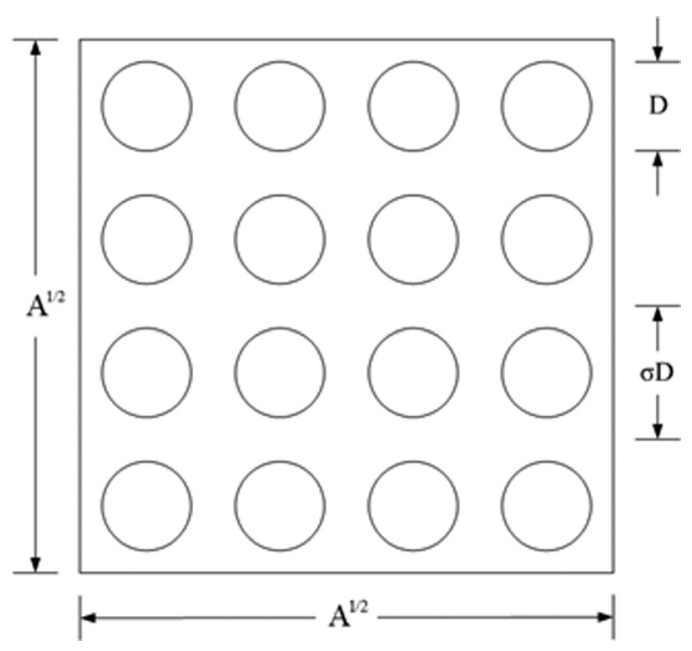

FIG. 4. Square array of horizontal cylinders.

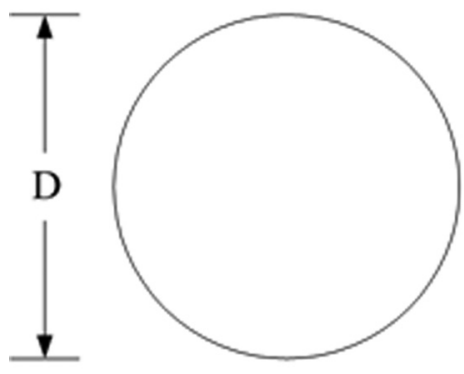

Round

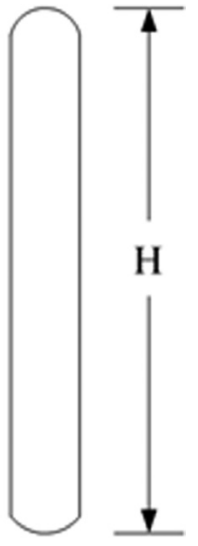

Flat
FIG. 5. Round tube versus flat tube.

where the factor $\mathrm{a}=\left[\mathrm{h}_{\mathrm{fg}} \mathrm{g} \rho / \mathrm{k} \nu\left(\mathrm{T}_{\mathrm{sat}}-\mathrm{T}_{\mathrm{w}}\right)\right]^{1 / 4}$ is a constant with the units $\mathrm{m}^{-3 / 4}$, cf. Eq. (8). From Eq. (11), we derive the total cooling rate for a two-sided wall of height $\mathrm{H}$,

$$
\mathrm{q}_{2 \mathrm{H}}^{\prime}=2 \mathrm{k}\left(\mathrm{T}_{\mathrm{sat}}-\mathrm{T}_{\mathrm{w}}\right) 0.943 \mathrm{a}\left(\frac{\pi}{2} \mathrm{D}\right)^{3 / 4},
$$

where we used $H=\pi \mathrm{D} / 2$. Dividing Eq. (14) by Eq. (13), we find that

$$
\frac{\mathrm{q}_{2 \mathrm{H}}^{\prime}}{\mathrm{q}_{\mathrm{D}}^{\prime}}=\left(\frac{2}{\pi}\right)^{1 / 4} \frac{0.943}{0.729}=1.16
$$

In conclusion, flattening the tube and orienting its cross section vertically has the effect of increasing the condensation rate by $16 \%$.

The reason for the superiority of the flattened tube is the elimination of the relatively horizontal portions of the circular cross section. The heat transfer coefficient for condensation on a horizontal plate with the length scale D and facing upward is ${ }^{12}$ (p. 441)

$$
\mathrm{h}_{\text {up }} \sim \frac{\mathrm{k}}{\mathrm{D}} \mathrm{a}^{4 / 5} \mathrm{D}^{3 / 5}
$$

This can be compared with the heat transfer coefficient on the side (vertical) surfaces of length D, cf. Eq. (8),

$$
\mathrm{h}_{\text {side }} \sim \frac{\mathrm{k}}{\mathrm{D}} \text { a } \mathrm{D}^{3 / 4}
$$

The ratio $h_{\text {up }} / h_{\text {side }} \sim\left(\mathrm{a} \mathrm{D}^{3 / 4}\right)^{-1 / 5}$ is considerably smaller than 1 , because the group $\left(\mathrm{aD}^{3 / 4}\right) \gg 1$ is of order $\overline{\mathrm{Nu}}_{\mathrm{D}}$, and in all thin-film flows $\overline{\mathrm{Nu}}_{\mathrm{D}}$ is much greater than 1 because it is the same as the slenderness ratio of the film.

\section{DISTRIBUTION OF MULTIPLE TUBE SIZES}

The traditional design consists of tubes of one size, which are distributed uniformly (with uniform spacing $\mathrm{S}$ ) over the condenser cross section A, or along the column of height $\mathrm{H}$. In this section, we explore the idea of using tubes 
of several sizes $\left(\mathrm{D}_{1}, \mathrm{D}_{2}, \ldots\right)$ and asking whether the bigger should be at the top of the column $\left(D_{1}>D_{2}>\ldots\right)$, or at the bottom $\left(\mathrm{D}_{1}<\mathrm{D}_{2}<\ldots\right)$.

We start with the observation that condensation on a tube of diameter $\mathrm{D}$ is equivalent in a scale-analysis sense to condensation on a vertical two-sided slab of height $\mathrm{D}$. This is why if we replace H with D in Eq. (11) we obtain a formula that is almost the same as Eq. (8). This observation leads us to Fig. 6, which allows us to view a vertical column of tubes (a) as a cold slab (b). The film of condensate forms on (b) in the same manner as on (a). It grows on the cooled spots of the slab $(1,2, \ldots)$ but not on the spots that correspond to the tube spacings $(\mathrm{S})$.

The condensation of steam on the falling film of height $\mathrm{S}$ is assumed to be negligible in comparison with the condensation rate due to a cold spot. Note the assumed constant thickness of the film that coats the slab (b) over the spots $S$ (in reality, in the space between two tubes, the film falls freely, and becomes narrower because of downward acceleration; this effect is neglected at this state).

Next, the flow rate of condensate on slab (b) is equivalent to the flow generated by the shorter slab (c) from which the adiabatic spots $(\mathrm{S})$ have been eliminated. The height of slab (c) is

$$
\mathrm{H}=\sum_{\mathrm{i}} \mathrm{D}_{\mathrm{i}}
$$

and its condensation rate can be estimated with Eq. (11), in which $\mathrm{H}$ has the value indicated in Eq. (18). The vertical dimension that drives the condensation process is the aggregate height of the multi-scale cylinders. This is also confirmed by replacing $\mathrm{nD}$ with $\mathrm{H}$ in Eqs. (9) and (10), and discovering a formula that is almost the same as Eq. (11).

The aggregate height of Eq. (18) does not depend on the order in which the tubes are arranged in the column, bigger at the top vs bigger at the bottom. In conclusion, the distribution of tube sizes in the vertical direction does not affect the condensation performance of the column. What matters is (a)

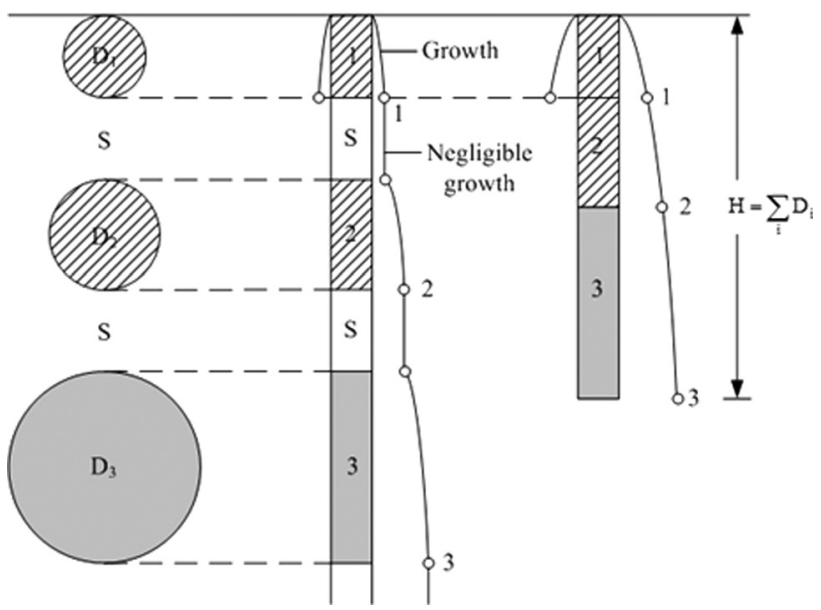

FIG. 6. Column of cylinders with different sizes. the aggregate height of the cold surfaces present in the column. A larger aggregate height is better.

\section{SMALLER TUBES}

Are smaller tubes better, and if so, how much better? Consider the vertical cross section (A) of the condenser, and assume that all the tubes have the same size (D), and are spaced equidistantly, as in Fig. 4. For clarity, assume that the tubes are arranged in a square pattern such that one tube occupies a square with the side $\sigma \mathrm{D}$, where $\sigma \gtrsim 1$. Assume that the array cross section $\mathrm{A}$ is square, $\mathrm{A}=\mathrm{H} \times \mathrm{H}$. There are $n$ columns, $n=H /(\sigma D)$, and in every column there are $n$ tubes. The cross section A contains $\mathrm{n}^{2}$ tubes.

The aggregate height of the cold surfaces of one column is $\mathrm{H}=\mathrm{n} \sigma \mathrm{D}$. The total cooling rate (proportional to condensation rate) from the two sides of one column is

$$
\mathrm{q}_{\mathrm{H}}^{\prime} \sim 2 \mathrm{k}\left(\mathrm{T}_{\mathrm{sat}}-\mathrm{T}_{\mathrm{w}}\right) \mathrm{a}(\mathrm{nD})^{3 / 4},
$$

where a is defined under Eq. (13). There are n columns, therefore, total condensation rate on $\mathrm{A}$ is

$$
\mathrm{q}_{\mathrm{A}}^{\prime} \sim 2 \mathrm{n} \mathrm{\textrm {q } _ { \mathrm { H } } ^ { \prime }} \text {. }
$$

The objective is to increase the condensation rate density,

$$
\frac{\mathrm{q}_{\mathrm{A}}^{\prime}}{\mathrm{A}}=\frac{2 \mathrm{n}}{\mathrm{A}} \mathrm{q}_{\mathrm{H}}^{\prime},
$$

which varies as $\mathrm{A}^{-1 / 8} \sigma^{-7 / 4} \mathrm{D}^{-1}$.

In conclusion, smaller tubes (D) are better if the liquid flow is laminar. On the other hand, smaller tubes required more pumping power for driving the cooling water through them. Smaller spacings $(\sigma)$ are also better, and a smaller cross sectional area (A) is marginally better. When the condenser volume is fixed, $\mathrm{B}=\mathrm{AL}$, a smaller $\mathrm{A}$ requires a larger $\mathrm{L}$, and this leads to a tradeoff between $\mathrm{A}$ and $\mathrm{L}$.

\section{VERTICAL SURFACES}

The conclusion from Fig. 5 is that vertical surfaces generate condensate faster than more complicated surfaces that contain horizontal patches. The most common configuration used in condensers is the round tube oriented horizontally. The horizontal portions are the polar zones (the nearly horizontal portions) of the circular cross section. There are two ways to eliminate the horizontal portions.

First, orient the round tube vertically. Assuming that in spite of the tube length (L), the film of condensate is still laminar, the total condensation rate is proportional to the total heat transfer rate,

$$
\mathrm{q}_{\mathrm{v}} \sim \mathrm{LDh}_{\mathrm{v}} \Delta \mathrm{T}
$$

where LD is the scale of the tube surface, $\Delta T=T_{\text {sat }}-T_{w}$, and $h_{v}$ is the heat transfer coefficient in the vertical-tube orientation,

$$
\mathrm{h}_{\mathrm{v}}=\frac{\mathrm{k}}{\mathrm{L}} \overline{\mathrm{Nu}}_{\mathrm{L}} \sim \frac{\mathrm{k}}{\mathrm{L}} \mathrm{aL}^{3 / 4}
$$


From this follows $\mathrm{q}_{\mathrm{v}} \sim \mathrm{LD} \Delta \mathrm{T} \mathrm{kaL}^{-1 / 4}$. The common orientation of the tube is horizontal, and in this case the total heat transfer rate scale is $\mathrm{q}_{\mathrm{h}} \sim \mathrm{LD} \Delta \mathrm{T}$ a $\mathrm{D}^{-1 / 4}$, because $\mathrm{D}$ is the vertical dimension. The ratio

$$
\frac{\mathrm{q}_{\mathrm{v}}}{\mathrm{q}_{\mathrm{h}}} \sim\left(\frac{\mathrm{D}}{\mathrm{L}}\right)^{1 / 4}
$$

indicates that $\mathrm{q}_{\mathrm{v}} \ll \mathrm{q}_{\mathrm{h}}$ because $\mathrm{L}$ is much greater than $\mathrm{D}$. This is why in designs with laminar film flow the tube is horizontal.

The comparison between $\mathrm{q}_{\mathrm{v}}$ and $\mathrm{q}_{\mathrm{h}}$ is quite different when $\mathrm{L}$ is large enough so that when oriented vertically the film is turbulent. The variation of $h_{v}$ with the vertical tube length ${ }^{13}$ is indicated in chart form in Ref. 12 (Fig. 10.5, p. 436),

$$
\frac{\mathrm{h}_{\mathrm{L}}}{\mathrm{k}}\left(\frac{\nu^{2}}{\mathrm{~g}}\right)^{1 / 3}=\left(\operatorname{Re}_{\mathrm{L}}^{-0.44}+5.82 \times 10^{-6} \operatorname{Re}_{\mathrm{L}}^{0.8} \operatorname{Pr}^{1.3}\right)^{1 / 2}
$$

In the large-L limit, the fully turbulent asymptote of this correlation is

$$
\frac{\mathrm{h}_{\mathrm{L}, \mathrm{turb}}}{\mathrm{k}}\left(\frac{\nu^{2}}{\mathrm{~g}}\right)^{1 / 3} \cong 0.00632 \mathrm{Re}_{\mathrm{L}}^{0.4}
$$

By combining Eqs. (5) and (6), we note the relation between heat transfer coefficient and mass flow rate of condensate, Eq. (7). In the case of the vertical tube, this relation is

$$
\mathrm{h}_{\mathrm{L}, \mathrm{turb}}=\frac{\Gamma_{\mathrm{L}} \mathrm{h}_{\mathrm{fg}}}{\mathrm{L} \Delta \mathrm{T}}
$$

Substituting this on the left side of Eq. (26), we obtain

$$
0.00265\left(\frac{\mathrm{L}}{\mathrm{m}}\right)^{-1} \operatorname{Re}_{\mathrm{L}}=0.00632 \mathrm{Re}_{\mathrm{L}}^{0.4}
$$

which delivers $\mathrm{Re}_{\mathrm{L}}$ as a function of tube length, $\operatorname{Re}_{\mathrm{L}}=4.255\left(\frac{\mathrm{L}}{\mathrm{m}}\right)^{5 / 3}$. Finally, in view of the definition $\operatorname{Re}_{\mathrm{L}}=\frac{4}{\mu} \Gamma_{\mathrm{L}}$, we use the properties listed in Sec. I and calculate $\Gamma_{\mathrm{L}}$ and the total mass flow rate of condensate,

$$
\dot{\mathrm{m}}_{\mathrm{L}, \mathrm{turb}}=\Gamma_{\mathrm{L}} \pi \mathrm{D}=3.34 \mu \mathrm{D}\left(\frac{\mathrm{L}}{\mathrm{m}}\right)^{5 / 3},
$$

where $\mathrm{L}$ is expressed in meters. This can be compared with the mass flow rate generated on the same tube in the horizontal position with laminar film flow,

$$
\dot{\mathrm{m}}_{\mathrm{D}, \mathrm{lam}}=\Gamma_{\mathrm{D}} \mathrm{L}=0.00046 \frac{\mathrm{kg}}{\mathrm{s} \cdot \mathrm{m}}\left(\frac{\mathrm{D}}{\mathrm{cm}}\right)^{3 / 4} \mathrm{~L}
$$

where D is expressed in centimeters. The ratio of mass flow rates

$$
\frac{\dot{\mathrm{m}}_{\mathrm{L}, \mathrm{turb}}}{\dot{\mathrm{m}}_{\mathrm{D}, \mathrm{lam}}}=0.566\left(\frac{\mathrm{L}}{\mathrm{m}}\right)^{2 / 3}
$$

indicates that in the vertical orientation the tube would produce more condensate when $\mathrm{L}$ exceeds $2.34 \mathrm{~m}$. At this critical length, Eq. (29) shows that the film Reynolds number is $\mathrm{Re}_{\mathrm{L}}=17.43$, which is consistent with upper limit of the $\mathrm{Re}_{\mathrm{L}}$ range for laminar flow in Fig. 7.

Second, one can keep the round tubes and position them horizontally, and, in addition, make vertical surfaces greater than the vertical (equatorial) sides that the circular cross section provides. This is accomplished by fusing the tube to a vertical plate fin that is collinear with the north-south direction of the tube cross section. This idea is related to flattening the tube (Fig. 5), except that it offers one advantage. Pumping cooling water through round tubes requires less power than pumping the same water flow rate through flat cross sectional areas: this aspect of constructal design of duct cross sections is discussed in detail in Ref. 8, Section 3.1.2.

\section{ARRAY OF FLATTENED TUBES}

In view of the comparison between flattened tubes and round tubes (Fig. 5), which showed that the flattened tube is superior, here we consider replacing the array of Fig. 4 with an array of flattened tubes. The new feature in the array is the elemental area shown in Fig. 7(b). In place of the square element $\sigma \mathrm{D} \times \sigma \mathrm{D}$, the flat tube of height $\mathrm{H}=\frac{\pi}{2} \mathrm{D}$ is centered in a rectangular element $\mathrm{y} \times \mathrm{x}$. The array $\mathrm{A}$ has $\mathrm{n}_{\mathrm{y}}=\mathrm{A}^{1 / 2} / \mathrm{y}$ flat tubes in a vertical column, and a total of $n_{x}=A^{1 / 2} / x$ columns. The condensation rate of one column is

$$
\Gamma_{\mathrm{n}_{\mathrm{y}} \mathrm{H}}=2 \mathrm{n}_{\mathrm{y}}^{3 / 4} \Gamma_{\mathrm{H}} .
$$

This corresponds to Eq. (11) of the array with round tubes. The total condensation rate produced by the array with flat tubes is

$$
\Gamma_{\mathrm{A}}=\mathrm{n}_{\mathrm{x}} 2 \mathrm{n}_{\mathrm{y}}^{3 / 4} \Gamma_{\mathrm{H}}
$$

Dividing this by Eq. (11), we obtain a measure of the effect of changing the elemental design, from round to flat in Fig. 6,

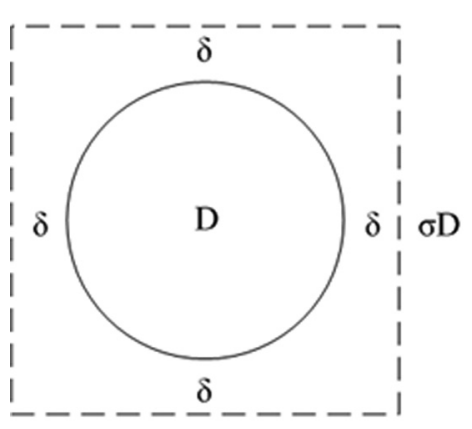

(a)

(b)

FIG. 7. Uniform spacings around tubes (round, flat) in an array. 


$$
\frac{\Gamma_{\mathrm{A}, \text { eq. } 33}}{\Gamma_{\mathrm{A}, \text { eq. } 11}}=\frac{2 \Gamma_{\mathrm{H}}}{\pi \Gamma_{\mathrm{D}}} \cdot \frac{(\sigma \mathrm{D})^{7 / 4}}{\mathrm{y}^{3 / 4} \mathrm{x}} .
$$

The analysis of Sec. IV showed that the front factor is $2 \Gamma_{\mathrm{H}} /\left(\pi \Gamma_{\mathrm{D}}\right)=1.16$. The second factor in Eq. (34) is more complicated because it depends on three freely changing features $(\sigma, \mathrm{y}, \mathrm{x})$. For a meaningful comparison of the two designs of Fig. 7, we assume that a single degree of freedom (the gap $\delta \ll \mathrm{D}$ ) controls the dimensions of the elemental areas, $\sigma \mathrm{D}=\mathrm{D}+2 \delta, \mathrm{y}=\mathrm{H}+2 \delta$, and $\mathrm{x}=2 \delta$. With this notation, Eq. (34) becomes

$$
\frac{\Gamma_{\mathrm{A}, \text { eq. } 33}}{\Gamma_{\mathrm{A}, \text { eq. } 11}}=0.356\left(1+2.545 \frac{\delta}{\mathrm{D}}+\cdots\right) \frac{\mathrm{D}}{\delta} .
$$

This ratio is equal to 2.69 when $\delta / \mathrm{D}=1 / 5$, and 4.47 when $\delta / \mathrm{D}=1 / 10$. In conclusion, the change from round tubes to flattened tubes in an array of the same size promises a dramatic increase in the total rate of condensation, or in the packing density of condensation.

\section{FORCED CONVECTION}

So far, we assumed that the removal of condensate from the cold surfaces is driven by gravity, and that the effect of the external movement of vapor is negligible. Here, we address the question of when the external flow is fast enough to govern the film condensation process. The answer follows from comparing the film condensation by natural convection, Eq. (8) with film condensation by forced convection ${ }^{14}$ (also Ref. 12, pp. 442-443),

$$
\overline{\mathrm{Nu}_{\mathrm{D}}}=0.64 \mathrm{Re}_{\mathrm{D}}^{1 / 2},
$$

where $\operatorname{Re}_{\mathrm{D}}=\mathrm{U}_{\infty} \mathrm{D} / \nu$ and $\mathrm{U}_{\infty}$ is the speed of the external flow and $\nu$ is the kinematic viscosity of liquid. Intersecting Eqs. (8) and (36), neglecting the leading factors 0.729 and 0.64 , and setting $\mathrm{D}=2 \mathrm{~cm}$, we find that the external flow is strong enough when $\mathrm{U}_{\infty} \gtrsim 7.7 \mathrm{~m} / \mathrm{s}$.

An alternative calculation of the $\mathrm{U}_{\infty}$ scale is based on the observation that the external flow of vapor plays an insignificant role when the shear stress on the vapor side $\left(\tau_{\mathrm{v}}\right)$ is smaller than the shear stress inside the liquid $\left(\tau_{1}\right)$. First, we evaluate $\tau_{1} \sim \mu \mathrm{V} / \delta$, where $\mathrm{V}$ is the downward velocity of the liquid film and $\delta$ is the film thickness. From $\overline{\mathrm{Nu}_{\mathrm{D}}}=$ $\mathrm{hD} / \mathrm{k}=\mathrm{q}^{\prime \prime} \mathrm{D} / \mathrm{k}\left(\mathrm{T}_{\mathrm{sat}}-\mathrm{T}_{\mathrm{w}}\right) \quad$ with $\quad \mathrm{q}^{\prime \prime} \sim \mathrm{k}\left(\mathrm{T}_{\mathrm{sat}}-\mathrm{T}_{\mathrm{w}}\right) / \delta$, where $\delta$ is the film thickness scale, we find that $\overline{\mathrm{Nu}_{\mathrm{D}}} \sim \mathrm{D} / \delta$ and $\delta \sim 0.006 \mathrm{~cm}$. Next, from $\Gamma_{\mathrm{D}} \sim \rho \delta \mathrm{V}$ we obtain $\mathrm{V} \sim \Gamma_{\mathrm{D}} \overline{\mathrm{Nu}_{\mathrm{D}}} /(\rho \mathrm{D})=1.36 \mathrm{~cm} / \mathrm{s}$. The shear stress across the liquid film is $\tau_{1} \sim \mu \mathrm{V} / \delta=0.16 \mathrm{~N} / \mathrm{m}^{2}$. Second, on the vapor side we assume laminar boundary layer flow, for which the shear stress scale is $\tau_{\mathrm{v}} \sim \frac{1}{2} \rho_{\mathrm{v}} \mathrm{U}_{\infty}^{2} \operatorname{Re}_{\mathrm{D}, \mathrm{v}}^{-1 / 2}$, where $\mathrm{Re}_{\mathrm{D}, \mathrm{v}}=$ $\mathrm{U}_{\infty} \mathrm{D} / \nu_{\mathrm{v}}$. Using the properties of saturated vapor at $38.4^{\circ} \mathrm{C}$, and setting $\mathrm{D}=2 \mathrm{~cm}$ and $\tau_{\mathrm{v}} \sim \tau_{1}$, we arrive at $\mathrm{U}_{\infty} \sim 25 \mathrm{~m} / \mathrm{s}$ as the external velocity scales below which the movement of the steam can be neglected.

The two estimates for $\mathrm{U}_{\infty}$ are of order $10 \mathrm{~m} / \mathrm{s}$. This means that external steam flows faster than $10 \mathrm{~m} / \mathrm{s}$ (in an order of magnitude sense) will affect the condensation results presented so far, which are for liquid films driven solely by gravity.

The developments reported in Secs. III-VIII for gravity driven film condensation can be constructed step by step for laminar film condensation driven by forced convection of steam with the free-stream speed $U_{\infty}$. For example, the forced-convection condensation on a tube (D) perpendicular to $\mathrm{U}_{\infty}$ is in accord with Eq. (36), which can be written as

$$
\frac{\overline{\mathrm{h}}_{\mathrm{D}} \mathrm{D}}{\mathrm{k}}=0.64 \mathrm{Re}_{\mathrm{D}}^{1 / 2} .
$$

The condensation augmentation effect due to flattening the tube to a long cross section of swept length $\mathrm{L}$ (where $2 \mathrm{~L}=\pi \mathrm{D}$, because the tube wall material is conserved) can be determined by comparing Eq. (37) with the corresponding result for the flattened tube. The heat transfer coefficient for laminar film condensation on one surface (L) parallel to $\mathrm{U}_{\infty}$ is ${ }^{15}$

$$
\frac{\overline{\mathrm{h}}_{\mathrm{L}} \mathrm{L}}{\mathrm{k}}=0.872 \operatorname{Re}_{\mathrm{L}}^{1 / 2}[1.508+\ldots]^{1 / 3} \cong \operatorname{Re}_{\mathrm{L}}^{1 / 2} .
$$

This formula is valid when the subcooling of the liquid is negligible $\left(\mathrm{Ja} \ll \operatorname{Pr}_{1}\right)$ and when $\left(\rho_{\mathrm{v}} \mu_{\mathrm{v}} / \rho_{1} \mu_{1}\right)^{1 / 2} \ll \mathrm{Ja} / \operatorname{Pr}_{1}$. Here, $\mathrm{Pr}_{1}$ is the liquid Prandtl number, and $\mathrm{Ja}$ is the Jakob number, $\mathrm{Ja}=\mathrm{c}_{\mathrm{P}}\left(\mathrm{T}_{\mathrm{sat}}-\mathrm{T}_{\mathrm{w}}\right) / \mathrm{h}_{\mathrm{fg}}$, which accounts for the subcooling of the liquid.

Next, Eq. (38) is transformed by noting that $\overline{\mathrm{h}}_{\mathrm{L}}=\overline{\mathrm{q}_{\mathrm{L}}^{\prime \prime}} / \Delta \mathrm{T}=\left(\mathrm{q}_{\mathrm{L}}^{\prime} / \mathrm{L}\right) / \Delta \mathrm{T}$, where $\mathrm{q}_{\mathrm{L}}^{\prime}$ is the total cooling rate provided by the surface L. Equation (38) becomes $\mathrm{q}_{\mathrm{L}}^{\prime}=\mathrm{k} \Delta \mathrm{TRe}_{\mathrm{L}}^{1 / 2}$. The flattened tube has two surfaces of length $\mathrm{L}$, and consequently it provides the cooling rate

$$
\mathrm{q}_{2 \mathrm{~L}}^{\prime}=2 \mathrm{k} \Delta \mathrm{TRe}_{\mathrm{L}}^{1 / 2} .
$$

The corresponding form of Eq. (37) is

$$
\mathrm{q}_{\mathrm{D}}^{\prime}=\pi \mathrm{k} \times 0.64 \operatorname{Re}_{\mathrm{D}}^{1 / 2}
$$

which comes from replacing $\overline{\mathrm{h}}_{\mathrm{D}}$ with $\overline{\mathrm{q}}_{\mathrm{D}}^{\prime \prime} / \Delta \mathrm{T}$ $=\mathrm{q}_{\mathrm{D}}^{\prime} /(\pi \mathrm{D}) / \Delta \mathrm{T}$. The ratio

$$
\frac{\mathrm{q}_{2 \mathrm{~L}}^{\prime}}{\mathrm{q}_{\mathrm{D}}^{\prime}}=\frac{2}{\pi \times 0.64}\left(\frac{\mathrm{Re}_{\mathrm{L}}}{\mathrm{Re}_{\mathrm{D}}}\right)^{1 / 2}=1.247
$$

is the same as the ratio $\Gamma_{2 \mathrm{~L}} / \Gamma_{\mathrm{D}}$, and indicates that flattening the tube and aligning its flat surfaces with the external flow has the effect of augmenting the condensation rate by roughly $25 \%$. This effect is greater than in gravity driven condensation, where it was $16 \%$, cf. Eq. (15).

The effect of alignment of tubes (round or flat) as columns parallel to $\mathrm{U}_{\infty}$ can be evaluated as follows. Consider a plate with the swept length $\mathrm{L}$, for which $\overline{\mathrm{h}}_{\mathrm{L}}$ is given by Eq. (38). A column of $\mathrm{n}$ such plates, arranged in line and with negligible spacings between them, has the corresponding heat transfer coefficient

$$
\frac{\overline{\mathrm{h}}_{\mathrm{nL}} \mathrm{nL}}{\mathrm{k}}=\mathrm{Re}_{\mathrm{nL}}^{1 / 2} .
$$


Dividing Eq. (42) by Eq. (38), we find that the overall heat transfer coefficient decreases significantly as $\mathrm{n}$ increases, i.e., as the column becomes longer

$$
\overline{\mathrm{h}}_{\mathrm{nL}}=\frac{\overline{\mathrm{h}}_{\mathrm{L}}}{\mathrm{n}^{1 / 2}} .
$$

The corresponding cooling rates of the nL-long column and the single $\mathrm{L}$ surface are $\mathrm{q}_{\mathrm{nL}}^{\prime}=\mathrm{k} \Delta \mathrm{T} \mathrm{Re} \mathrm{nL}^{1 / 2}$ and $\mathrm{q}_{\mathrm{L}}^{\prime}=\mathrm{k} \Delta \mathrm{T} \operatorname{Re}_{\mathrm{L}}^{1 / 2}$. Their ratio

$$
\frac{\mathrm{q}_{\mathrm{nL}}^{\prime}}{\mathrm{q}_{\mathrm{L}}^{\prime}}=\frac{\Gamma_{\mathrm{nL}}}{\Gamma_{\mathrm{L}}}=\mathrm{n}^{1 / 2}
$$

indicates that the longer column offers a larger condensation rate, but the effect of size (n) is weakened by the $1 / 2$ exponent. The corresponding exponent of $n$ for gravity driven condensation was 3/4, cf. Eq. (10). In conclusion, the negative effect of alignment of multiple surfaces is stronger in forced convection than in natural convection. This makes all the conclusions reached for gravity driven flow even more critical for forced convection. Arrays of tubes (round or flat) in cross flow can be analyzed as for gravity driven condensation, but relying on forced convection formulas such as Eqs. (37), (38), and (42).

\section{NUMBER OF TUBES IN ONE COLUMN}

We learned from Eq. (44) and from its analog for a column of tubes $\left(\mathrm{q}_{\mathrm{nD}}^{\prime} / \mathrm{q}_{\mathrm{D}}^{\prime}=\mathrm{n}^{1 / 2}\right)$ that as the number (n) of surfaces aligned in the column increases, the total cooling rate $\left(\mathrm{q}_{\mathrm{nD}}^{\prime}\right.$, or $\left.\Gamma_{\mathrm{nD}}\right)$ increases by a factor $\mathrm{n}$ raised to an exponent smaller than 1 , namely, $1 / 2$ in forced convection, and $3 / 4$ in natural convection. This means that the largest contributor to $\mathrm{q}_{\mathrm{nD}}^{\prime}$ is the leading surface (tube or plate) and that the weakest contributor is the trailing surface.

This observation leads to the idea proposed in Fig. 8. A column of $n$ tubes of length $\mathrm{L}$ is oriented in cross flow, with $\mathrm{U}_{\infty}$ aligned with the column. We ask whether this construct offers a greater condensation rate than a single tube of total

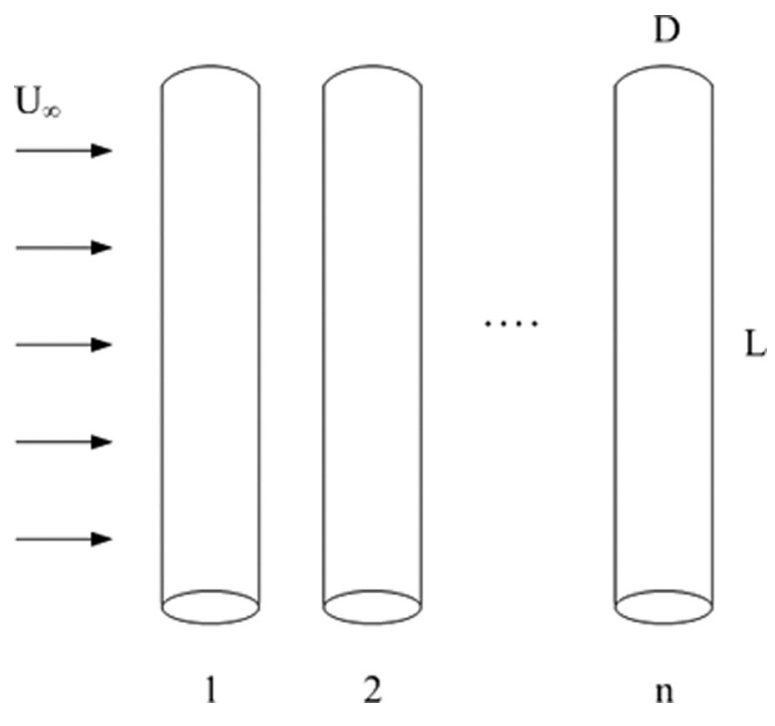

FIG. 8. Row of parallel tubes in cross flow. length $\mathrm{L}_{\mathrm{T}}=\mathrm{nL}$, which is also oriented in cross flow. We start with the total cooling rate provided by the n-column shown in Fig. 8,

$$
\mathrm{q}_{\mathrm{n}=} \mathrm{q}_{\mathrm{nD}}^{\prime} \mathrm{L}=\mathrm{n}^{1 / 2} \mathrm{q}_{\mathrm{D}}^{\prime} \mathrm{L}
$$

where $\mathrm{q}_{\mathrm{D}}^{\prime}=\pi \mathrm{D} \overline{\mathrm{h}}_{\mathrm{D}} \Delta \mathrm{T}$, and $\overline{\mathrm{h}}_{\mathrm{D}}$ is given by Eq. (37). Equation (45) becomes

$$
\mathrm{q}_{\mathrm{n}}=0.64 \pi \operatorname{Re}_{\mathrm{D}}^{1 / 2} \mathrm{k} \Delta \mathrm{T} \mathrm{L}_{\mathrm{T}} \mathrm{n}^{-1 / 2},
$$

with the observation that in the definition of $\Delta \mathrm{T}=\mathrm{T}_{\mathrm{sat}}-\mathrm{T}_{\mathrm{w}}$ the tube wall temperature is assumed uniform, from the tube inlet to the tube outlet. This assumption is appropriate when the tube length $\mathrm{L}$ is small enough.

When there is only one tube of length $\mathrm{L}_{\mathrm{T}}$ in cross flow, the temperature of the cooling water $\left(\dot{m} c_{P}\right)$ increases from the tube inlet to the outlet. This increase accounts for the reduced cooling rate provided by the single tube,

$$
\mathrm{q}_{1}=\dot{\mathrm{m}} \mathrm{c}_{\mathrm{P}}\left(\mathrm{T}_{\mathrm{w}, \text { out }}-\mathrm{T}_{\mathrm{w}, \text { in }}\right)=\dot{\mathrm{m}} \mathrm{c}_{\mathrm{P}}\left(\mathrm{T}_{\mathrm{sat}}-\mathrm{T}_{\mathrm{w}, \text { in }}\right) \varepsilon,
$$

where $\mathrm{T}_{\mathrm{sat}}-\mathrm{T}_{\mathrm{w} \text {,in }}$ is the same as the $\Delta \mathrm{T}$ used above, $\varepsilon$ is the effectiveness of the single tube in isothermal cross flow, $\varepsilon=1-\mathrm{e}^{-\mathrm{N}}$, and $\mathrm{N}$ is the number of heat transfer units, assumed constant,

$$
\mathrm{N}=\frac{\overline{\mathrm{h}}_{\mathrm{D}} \mathrm{A}_{\mathrm{D}}}{\dot{\mathrm{m} \mathrm{c}_{\mathrm{P}}}}, \quad \mathrm{A}_{\mathrm{D}}=\pi \mathrm{DL}_{\mathrm{T}} .
$$

The heat transfer rate for the $\mathrm{n}$ parallel tubes obtained from segmenting the tube length $\mathrm{L}_{\mathrm{T}}$ is expressed by

$$
\begin{aligned}
\mathrm{q}_{\mathrm{n}} & =\mathrm{n}^{-1 / 2} \cdot\left[\overline{\mathrm{h}}_{\mathrm{D}} \cdot(\pi \mathrm{D}) \cdot\left(\mathrm{T}_{\mathrm{sat}}-\mathrm{T}_{\mathrm{w}, \mathrm{in}}\right)\right] \cdot(\mathrm{nL}) \\
& =\mathrm{n}^{-1 / 2} \cdot\left(\overline{\mathrm{h}}_{\mathrm{D}} \mathrm{A}_{\mathrm{D}}\right) \cdot\left(\mathrm{T}_{\mathrm{sat}}-\mathrm{T}_{\mathrm{w}, \text { in }}\right) .
\end{aligned}
$$

Equation (49) overestimates the heat transfer rate $\mathrm{q}_{\mathrm{n}}$ because the tube wall temperature increases along with the cooling water temperature along the flow path. By assuming that the tube wall is very thin with a very high thermal conductivity, the cooling water bulk temperature is nearly the same as the outside tube wall temperature. The mean temperature for a segmented tube with the length $\mathrm{L}=\mathrm{L}_{\mathrm{T}} / \mathrm{n}$ is

$$
\overline{\mathrm{T}_{\mathrm{sat}}-\mathrm{T}_{\mathrm{w}}}=\frac{1}{\mathrm{~L}} \int_{\mathrm{x}=0}^{\mathrm{x}=\mathrm{L}}\left(\mathrm{T}_{\mathrm{sat}}-\mathrm{T}_{\mathrm{w}}\right) \mathrm{dx} \text {. }
$$

The effectiveness of a tube of length $\mathrm{L}$ is defined by assuming that the cooling water flow rate through the tube of length $\mathrm{L}$ is the same $\dot{\mathrm{m}}$ as the one flowing through the tube $\mathrm{L}_{\mathrm{T}}$,

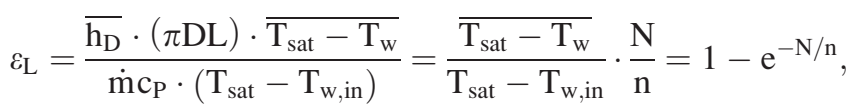

such that

$$
\overline{\mathrm{T}_{\mathrm{sat}}-\mathrm{T}_{\mathrm{w}}}=\left(\mathrm{T}_{\mathrm{sat}}-\mathrm{T}_{\mathrm{w}, \text { in }}\right) \cdot\left(1-\mathrm{e}^{-\mathrm{N} / \mathrm{n}}\right) \cdot \frac{\mathrm{n}}{\mathrm{N}} .
$$


$\mathrm{q}_{\mathrm{n}}$ is revised by replacing $\mathrm{T}_{\mathrm{s}}-\mathrm{T}_{\mathrm{w}}$, in in Eq. (49) with the mean temperature difference expression of Eq. (52)

$$
\mathrm{q}_{\mathrm{n}}=\left(\dot{\mathrm{m}} \mathrm{c}_{\mathrm{P}}\right) \cdot \mathrm{n}^{1 / 2} \cdot\left(\mathrm{T}_{\mathrm{sat}}-\mathrm{T}_{\mathrm{w}, \mathrm{in}}\right) \cdot\left(1-\mathrm{e}^{-\mathrm{N} / \mathrm{n}}\right) .
$$

The global thermal performance of the $\mathrm{n}$ column relative to the single tube is indicated by the ratio $\mathrm{q}_{\mathrm{n}} / \mathrm{q}_{1}$,

$$
\frac{\mathrm{q}_{\mathrm{n}}}{\mathrm{q}_{1}}=\mathrm{n}^{1 / 2} \cdot \frac{1-\mathrm{e}^{-\mathrm{N} / \mathrm{n}}}{1-\mathrm{e}^{-\mathrm{N}}} .
$$

Differentiating $\mathrm{q}_{\mathrm{n}} / \mathrm{q}_{1}$ with respect to tube number $\mathrm{n}$ and then set zero for a fixed $\mathrm{N}$, a transcendental equation is obtained

$$
1=\mathrm{e}^{-\mathrm{N} / \mathrm{n}} \cdot\left(1+2 \cdot \frac{\mathrm{N}}{\mathrm{n}}\right),
$$

which yields $\mathrm{N} / \mathrm{n}=1.256$. Figure 9 shows the $\mathrm{q}_{\mathrm{n}} / \mathrm{q}_{1}$ values according to increasing the number of tube segments $n$, for a fixed $N$. The ratio $\left(q_{n} / q_{1}\right)_{m}$ reaches a maximum that depends on $\mathrm{N}$. For example, $\mathrm{n} \cong 8,16,32$ for $\mathrm{N} \cong 10,20,40$, respectively. The optimal number of segments is $\mathrm{n}_{\mathrm{opt}}$ $=0.796 \mathrm{~N}$. The maximized ratio $\mathrm{q}_{\mathrm{n}} / \mathrm{q}_{1}$ that corresponds to $\mathrm{n}_{\text {opt }}$ is plotted versus $\mathrm{N}$ in Fig. 10. When $\mathrm{N} \gg 1$ (and $\mathrm{n} \gg 1$ ), the ratio $\mathrm{q}_{\mathrm{n}} / \mathrm{q}_{1}$ increases in proportion with $\mathrm{N}^{1 / 2}$.

Combining $\mathrm{n}=0.796 \mathrm{~N}$ with Eqs. (48), (37) and $\mathrm{L}_{\mathrm{T}}=\mathrm{nL}$, we arrive at the length of one tube,

$$
\mathrm{L}=1.28 \frac{\dot{\mathrm{m}} \mathrm{c}_{\mathrm{P}}}{\mathrm{kRe}_{\mathrm{D}}^{1 / 2}}
$$

where $\operatorname{Re}_{\mathrm{D}}=\mathrm{U}_{\mathrm{avg}} \mathrm{D} / \nu_{\mathrm{v}}$, and $\mathrm{U}_{\mathrm{avg}}$ is the average free stream velocity of the vapor that sweeps the tubes. The vapor enters the column of $n$ parallel tubes with the velocity $\mathrm{U}_{\infty}$, and exits with a velocity close to zero, because the vapor condenses as it sweeps the n column. Therefore, in the following analysis, we assume that $\mathrm{U}_{\mathrm{avg}} \cong \mathrm{U}_{\infty} / 2$.

Next, we consider the volume occupied by the n column, and invoke the first law of thermodynamics. The difference between the enthalpy stream brought in by the vapor and the enthalpy carried away by the condensate is $\dot{\mathrm{m}}_{\mathrm{v}} \mathrm{h}_{\mathrm{fg}}$, where $\dot{\mathrm{m}}_{\mathrm{v}}=\rho_{\mathrm{v}} \mathrm{U}_{\infty} \sigma \mathrm{DL}$, and $\sigma \mathrm{DL}$ is the cross sectional area of the vapor inlet. The same enthalpy difference is absorbed by the

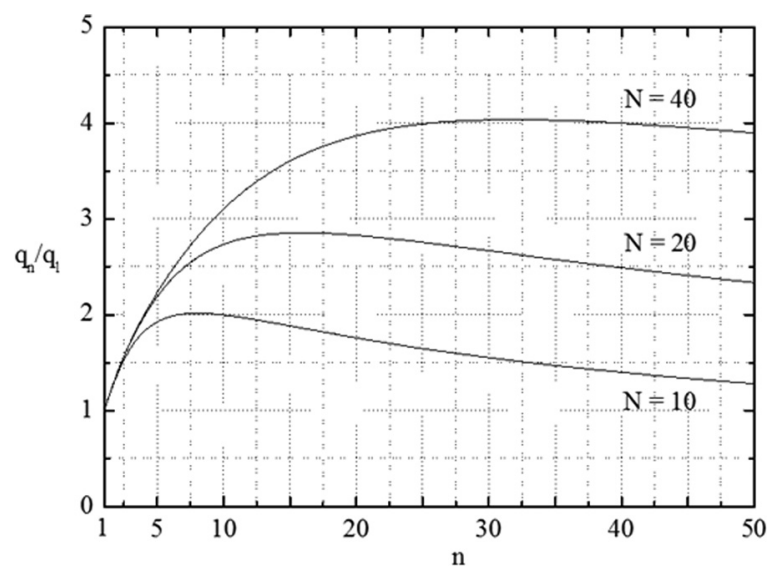

FIG. 9. The advantage of dividing the cold tube into the right number of segments.

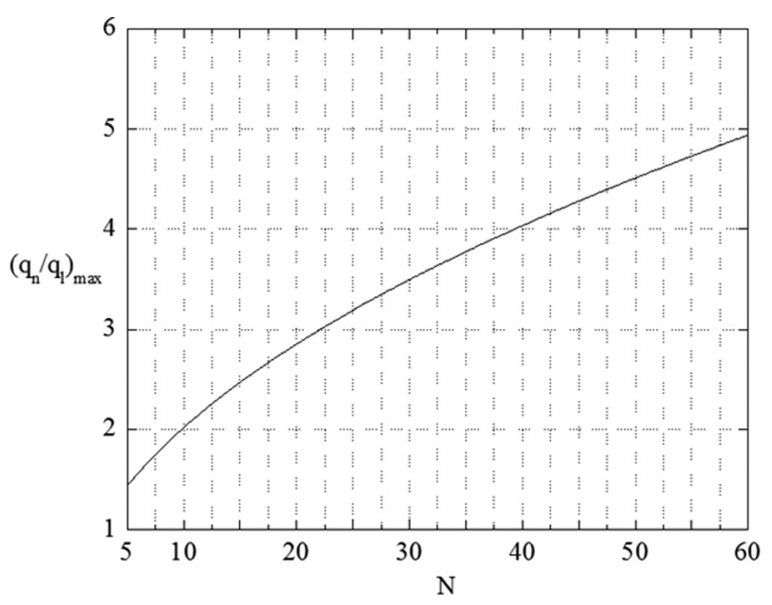

FIG. 10. The peak condensation density associated with segmenting the cold cylinder optimally.

(n $\dot{\mathrm{m}})$ stream of cooling water, namely, $\mathrm{n} \dot{\mathrm{m}} \mathrm{c}_{\mathrm{P}}\left(\mathrm{T}_{\mathrm{sat}}-\mathrm{T}_{\mathrm{w}, \mathrm{in}}\right) \varepsilon$, where $\varepsilon=1-\mathrm{e}^{-\mathrm{N} / \mathrm{n}}$ and $\mathrm{N} / \mathrm{n}=1.256$. From this first-law balance results

$$
\mathrm{L}_{\mathrm{T}}=4.56 \frac{\mathrm{h}_{\mathrm{fg}} \rho_{\mathrm{v}} \sigma \dot{\mathrm{m}} \mathrm{c}_{\mathrm{P}} \nu_{\mathrm{v}}}{\mathrm{k}^{2}\left(\mathrm{~T}_{\mathrm{sat}}-\mathrm{T}_{\mathrm{w}, \mathrm{in}}\right)} .
$$

In conclusion, the total tube length $\mathrm{L}_{\mathrm{T}}$ is proportional to the mass flow rate through the tube. Dividing Eq. (57) by Eq. (56), we obtain the number of tubes in the column,

$$
\mathrm{n}=3.571 \frac{\mathrm{h}_{\mathrm{fg}} \mu_{\mathrm{v}} \sigma}{\mathrm{k}\left(\mathrm{T}_{\mathrm{sat}}-\mathrm{T}_{\mathrm{w}, \text { in }}\right)} \operatorname{Re}_{\mathrm{D}}^{1 / 2},
$$

where

$$
\operatorname{Re}_{\mathrm{D}}=\frac{\left(\mathrm{U}_{\infty} / 2\right) \mathrm{D}}{\nu_{\mathrm{v}}}=\frac{\mathrm{D}}{2 \nu_{\mathrm{v}}} \frac{\dot{\mathrm{m}}_{\mathrm{v}}}{\sigma \mathrm{DL} \rho_{\mathrm{v}}},
$$

and, after using Eq. (56) to eliminate L,

$$
\operatorname{Re}_{\mathrm{D}}^{1 / 2}=\frac{1}{2(1.28) \sigma} \frac{\dot{\mathrm{m}}_{\mathrm{v}}}{\dot{\mathrm{m}}} \frac{\mathrm{k}_{\mathrm{v}}}{\mu_{\mathrm{v}} \mathrm{c}_{\mathrm{P}}} .
$$

Using the saturated steam properties listed at the start of Sec. II, we find that $\mathrm{k}_{\mathrm{v}} /\left(\mu_{\mathrm{v}} \mathrm{c}_{\mathrm{P}}\right)=0.228$, and Eq. (60) becomes

$$
\operatorname{Re}_{\mathrm{D}}^{1 / 2}=\frac{0.0892}{\sigma} \frac{\dot{\mathrm{m}}_{\mathrm{v}}}{\dot{\mathrm{m}}} .
$$

Together, Eqs. (58) and (61) indicate that the mass flow rate ratio (cooling water/steam) in the condenser should be

$$
\frac{\mathrm{n} \dot{\mathrm{m}}}{\dot{\mathrm{m}}_{\mathrm{v}}}=95.35
$$

This result agrees in an order of magnitude sense with (but should not be confused with) the estimate obtained by writing the approximate enthalpy change balance

$$
\dot{\mathrm{m}}_{\mathrm{v}} \mathrm{h}_{\mathrm{fg}} \cong \mathrm{n} \dot{\mathrm{m}} \mathrm{c}_{\mathrm{P}}\left(\mathrm{T}_{\mathrm{sat}}-\mathrm{T}_{\mathrm{w}}\right)
$$

which leads numerically to $\mathrm{n} \dot{\mathrm{m}} / \dot{\mathrm{m}}_{\mathrm{v}} \cong 68.35$. 


\section{CONCLUSION}

The chief conclusion of this work is that, in accord with the evolutionary design phenomenon previewed in Fig. 2, it is possible to increase the global rate of condensation in a fixed volume by varying freely and without bias the morphology of the flow system. To start, this means to vary the shapes and arrangement of the cooled solid surfaces on which condensation occurs.

We found that this approach leads to stepwise significant increases in global condensation rate. For example, the use of vertically flat tube cross sections (as opposed to round tubes) promises increases of order $16 \%$ in gravity driven condensation and $25 \%$ in condensation driven by forced external flow. These advantages hold for single tubes as well as for arrays of tubes. The length of one tube and the number of tubes in one column are also geometric features that can be varied and selected in order to increase the global rate of condensation.

According to one of the reviewers, this paper makes several contributions to applied physics:

(i) The evolution of technology is described in terms of the special time direction of the useful (purposeful) changes in the configuration (shapes, arrangements) of surfaces on which flow/condensation occurs, e.g., Figs. 1 and 2. This explains what "evolution" means. It is an important step for physics, not just technology. ${ }^{16}$

(ii) The analogy between the naturally evolving solidification design (the snowflake) and the evolution of condensation surfaces (Figures 1 and 2) is educational.

(iii) On the practical side, the path to increasing the "density" of condensation is to change (morph) freely and without preconceptions all the features of the flow architecture. This is the fundamental principle of physics, which empowers all technology evolution.

(iv) Along this route, the paper shows that stepwise increases in global performance (density) are possible, well beyond the performance of classical designs: flattened tubes, multi-size tubes, vertical instead of horizontal, forced convection film instead of gravity driven film, optimal tube length, optimal number of tubes in line, and more. In the future, the objective of decreasing the pumping power may be considered in tandem with the objective of increasing the heat transfer density.

${ }^{1}$ S. Kakac, Boilers, Evaporators, and Condensers (Wiley, New York, 1991).

${ }^{2}$ R. E. Putman, Steam Surface Condensers: Basic Principles, Performance Monitoring, and Maintenance (ASME Press, New York, 2001).

${ }^{3}$ C. Zhang, A. C. M. Sousa, and J. E. S. Venart, "The numerical and experimental study of a power plant condenser," J. Heat Transfer 115, 435-445 (1993).

${ }^{4}$ M. M. Prieto, E. Montanes, and O. Menendez, "Power plant condenser performance forecasting using a non-fully connected artificial neural network," Energy 26, 65-79 (2001).

${ }^{5} \mathrm{C}$. Zhang, "Numerical modeling using a quasi-three-dimensional procedure for large power plant condensers," J. Heat Transfer 116, 180-188 (1994).

${ }^{6} \mathrm{C}$. Zhang and A. Bokil, "A quasi-three-dimensional approach to simulate the two-phase fluid flow and heat transfer in condensers," Int. J. Heat Mass Transfer 40, 3537-3546 (1997).

${ }^{7}$ A. Bejan, Advanced Engineering Thermodynamics, 3rd ed. (Wiley, Hoboken, 2006).

${ }^{8}$ A. Bejan and S. Lorente, Design With Constructal Theory (Wiley, Hoboken, 2008).

${ }^{9}$ A. Bejan and S. Lorente, "Constructal law of design and evolution: Physics, biology, technology, and society," J. Appl. Phys. 113, 151301 (2013).

${ }^{10}$ A. Bejan, "Maxwell's demons everywhere: Evolving design as the arrow of time," Sci. Rep. 4, 4017 (2014).

${ }^{11}$ A. Bejan, S. Lorente, B. S. Yilbas, and A. Z. Sahin, "Why solidification has an S-shaped history," Sci. Rep. 3, 1711 (2013).

${ }^{12}$ A. Bejan, Convection Heat Transfer, 4th ed. (Wiley, Hoboken, 2013).

${ }^{13}$ S. L. Chen, F. M. Gerner, and C. L. Tien, "General film condensation correlations," Exp. Heat Transfer 1, 93-107 (1987).

${ }^{14}$ I. G. Shekriladze and V. I. Gomelauri, "Theoretical study of laminar film condensation of flowing vapour," Int. J. Heat Mass Transfer 9, 581-591 (1966).

${ }^{15} \mathrm{~J}$. W. Rose, "A new interpolation formula for forced-convection condensation on a horizontal surface," J. Heat Transfer 111, 818-819 (1989).

${ }^{16}$ A. Bejan, J. D. Charles, and S. Lorente, "The evolution of airplanes," J. Appl. Phys. 116, 044901 (2014). 